\title{
A TEORIA DE CESARE LOMBROSO E SUA INFLUÊNCIA NA SOCIEDADE
}

\section{ARTIGO ORIGINAL}

MACHADO, Daniel Dias ${ }^{1}$

MACHADO, Daniel Dias. Et al. A teoria de Cesare Lombroso e sua influência na sociedade. Revista Científica Multidisciplinar Núcleo do Conhecimento. Ano 06, Ed. 01, Vol. 07, pp. 57-73. Janeiro de 2021. ISSN: 2448-0959, Link de acesso: https://www.nucleodoconhecimento.com.br/lei/cesare-lombroso

\section{RESUMO}

Este artigo tem como objetivo analisar as teorias do médico e criminologista Cesare Lombroso e vincular sua influência às práticas racistas que ocorreram em larga escala no Brasil, a fim de melhorar a educação, a política e o campo econômico. Os métodos

1 Tecnólogo em Comércio Exterior pelo Instituto Brasileiro de Gestão Empresarial (IBGEN) de Porto Alegre, Paralegal em Conciliação, Mediação e Arbitragem pela Crown University of Bradenton, Bacharel em Ciências Jurídicas Estrangeiras pela Crown University of Bradenton, Tecnólogo em Serviços Jurídicos e Notariais pelo Instituto Brasileiro de Treinamento (IBF) de Joinville e Bacharel em Psicologia pela Escola Superior Batista do Amazonas (ESBAM). Da mesma forma, completou duas especializações, em Criminologia na Faculdade Famart de Itaúna e em Ética e Justiça na Harvard University em Massachusetts. Possui Mestrado em Administração com Menção em Gestão Organizacional pela Universidad Nacional Experimental de Los Llanos Occidentales Ezequiel Zamora de Santa Bárbara, Doutorado em Ciências Jurídicas pela Crown University de Bradenton e Pós-doutorado em Aplicação da Ontologias para Gestão do Conhecimento pela Crown University de Bradenton na condição de dupla diplomação com o programa de Pós-doutorado em Ontologia do Conhecimento e sua Transcendência da Perspectiva Educacional, e sua aplicação na Gestão Organizacional pela Universidade Fermín Toro de Lara. 
utilizados neste trabalho serão bibliográficos e de registro, buscando destacar as ideias de especialistas no campo da criminologia e a discriminação de minorias étnicas no Brasil. Na conclusão principal, é necessário formular políticas profundas de ação de igualdade de direitos para resolver os problemas causados por processos históricos e teorias bem planejadas de eugenia e racismo.

Palavras-chave: Criminologia, processos históricos, políticas de ação.

\section{INTRODUÇÃO}

Em 1876, Cesare Lombroso, um criminologista e médico, publicou seu livro mais notório "O Homem Delinquente". Neste artigo, o autor se concentra em sua pesquisa sobre a identificação de criminosos e criminosos através de aspectos genéticos e físicos (incluindo o uso de padrões estabelecidos). Este trabalho também foi muito bem-vindo e persistiu entre os estudiosos positivistas que seguiram o fenômeno da criminologia no século XIX. No entanto, ao longo dos séculos 20 e 21, essa pesquisa mostrou-se insuficiente para determinar quais pessoas são criminosas e podem não ser criminosas, que perderam amplamente sua validade científica.

Entretanto, os preconceitos e estereótipos dessa teoria ainda não atingiram o mesmo estado de escassez, mas ainda apresentam características óbvias no senso comum da população brasileira, causando discriminação contra minorias e mostrando que a democracia étnica brasileira está longe de ser concretizada, ou seja, racismo velado se espalhado amplamente.

Em vista desses fatos, este estudo tem como objetivo analisar as teorias do médico e criminologista Cesar Lombroso e vincular seu impacto às práticas racistas de grande escala que ocorreram no território brasileiro, assim, em educação, política e economia. O domínio tem um impacto. Os métodos utilizados neste trabalho serão bibliográficos e de registro, buscando destacar as ideias de especialistas no campo da criminologia e a discriminação de minorias étnicas no Brasil. 


\section{BIOGRAFIA DE CESARE LOMBROSO}

Cesare Lombroso nasceu em Verona em 1835 e é famoso por Romeu e Julieta. Ele queria estudar medicina e estudou na Universidade de Pavia e se formou em 1858 aos 23 anos. Profissionalmente, ele é médico e filósofo (AFONSO, 2014).

Quando era médico especializado em psiquiatria, ele imediatamente começou a praticar medicina. Quando foi apontado como chefe do abrigo na cidade de Pesaro, começou a estabelecer contato com pacientes mentais e dedicou a maior parte de seu estudo e vida a eles. Quando ele associa demência ao crime, sua experiência psiquiátrica é importante. Sua experiência neste campo lançou as bases para a criação de "Genius and Madness", publicada em 1870 (BITENCOURT, 2011).

Logo, ele também se tornou médico na prisão de Turim e em outras cidades. Ele foi apontado como médico militar, o que provou sua conexão intelectual com criminosos e soldados, especialmente marinheiros. Marinheiros participaram da maior parte de sua pesquisa, e aos 30 anos assume a cátedra na Faculdade de Medicina de Turim, que só deixou no final de sua vida (CARVALHO, 2010).

\subsection{OBRAS}

- 1874 -Gênio e loucura

- 1876 -O homem delinquente

- 1891 -O delito

- 1891 -O antissemitismo e as ciências modernas

- 1893 -A mulher delinquente, a prostituta e a mulher normal

- 1893 -As mais recentes descobertas e aplicações da psiquiatria e antropologia criminal

- 1894 - Os anarquistas

- 1894 - O crime, causas e remédios 


\section{A TEORIA DO CRIMINOSO NATO E SUAS PRINCIPAIS CARACTERÍSTICAS}

Os estudiosos clássicos da criminologia também apontaram que os interesses sociais de algumas pessoas às custas de outras promovem comportamentos criminosos, e esses comportamentos devem ser calculados em média entre a população de uma região, distribuição. O nome principal da Escola Pública, Marquês, destacou em seu livro principal "Dos Delitos e Das Penas" que é necessário combater a ambiguidade da lei, pois estão cheios de termos técnicos que só são consistentes com advogados. Portanto, ele deve ser escrito em um idioma comum para que todos os cidadãos possam entendê-lo. Além disso, Demiranda também criticou fortemente, sentenciou e prendeu desumano (DEMIRANDA, 2015).

A escola criminosa positivista quebrou todas as suposições e reivindicações da escola clássica e foi fortemente influenciada pelos evolucionistas Charles Darwin e Herbert Spencer e pelo positivista Augusto Conte. Por sua vez, devido a fatores sociais, naturais e biológicos, essa escola considera o crime um fenômeno natural. Dessa maneira, os pensadores positivistas negam que pessoas racionais possam exercer 0 livre arbítrio. Como afirmam os clássicos, eles acreditam que os criminosos serão expostos à força, sem conhecer as razões para si mesmos. Tais razões podem ser psicológicas, físicas e psicológicas (VIEIRA, 2008).

O nome principal da escola positivista é Cesare Lombroso, psiquiatra, cirurgião e higienista responsável pelo estabelecimento da antropologia criminal. Mota descreveu a visão de Lombroso:

Lombroso entendia o crime como um fato real, que perpassa todas as épocas históricas, natural e não como uma fictícia abstração jurídica. Como fenômeno natural que é, o crime tem que ser estudado primacialmente em sua etiologia, isto é, a identificação das suas causas como fenômeno, de modo a se poder combatê-lo em sua própria raiz, com eficácia, com programas de prevenção realistas e científicos (MOTA, 2007). 
Durante a produção do trabalho, foram analisados aproximadamente 25.000 prisioneiros na Europa e mais de 400 resultados de autópsia. Após análise, Lombroso concluiu que, se uma pessoa apresenta várias características físicas, como assimetria do crânio, escape da testa, orelhas aladas, protrusão óssea, crânio menor, arco superciliar significativo, protrusão maxilar Rosto largo, órgãos sexuais anormais, cabelos ricos, corpo alto, braços muito longos, mãos grandes, insensibilidade, alívio da dor, mania (prioridade ao uso da mão esquerda), membros comprometidos (não acostumados a usar a mão) e vulnerabilidade são a capacidade dos indivíduos de se recuperar rapidamente de traumas físicos. Para mulheres com potencial criminoso, isso é atribuído a características relacionadas à masculinidade, como cordas vocais grossas, excesso de pelos no corpo e verrugas. Além disso, em relação às características psicológicas dos criminosos nascidos, haverá dormência moral, impulsividade, vaidade, preguiça, cinismo, imprevisibilidade, tendências a tatuar e ingenuidade (SILVA, 2010).

Lombroso também acredita que criminosos são incentivos hereditários, que são transmitidos de geração em geração de maneira genética e, portanto, acreditam na existência de "genes criminosos". Maurício Mota destacou que, segundo Lombroso, o comportamento inútil do crime será um retorno evolutivo, uma série de "estigma" provará o comportamento rude do agressor (o produto do retorno, não a evolução das espécies). Segundo ele, os criminosos sofreram uma série de degradação, estigma comportamental, psicológico e social (SANTOS, 2014).

Ao explicar o conceito de crime inútil, Charles Darwin publicou o livro Origin of Species em 1859, mostrando sua "natureza evolutiva" por meio da seleção natural. De acordo com essa teoria, os organismos transmitem aos seus filhos as características que provavelmente permitirão que a espécie sobreviva. Portanto, a variação de espécies pode ser explicada pouco a pouco de uma geração para a seguinte (SANTORO FILHO, 2015).

Além de Cesare Lombroso, também podemos citar outros nomes de referência da escola positivista de criminologia, como Enrico Ferry e Rafi, defensores da obra "Cruel Criminals" Gallofallo. Embora essas características tenham sido amplamente aceitas 
no momento da publicação, a comunidade científica não as utilizou em pesquisas criminológicas subsequentes, segundo Pablos de Molina (1999), a razão para esse fato é que, no final do século XIX, surgiu a primeira noção de luta de classes e desigualdade causada pelo sistema capitalista. Isso inspirou os estudiosos do crime a acreditar que se tratava de um comportamento em grande parte ilegal devido a razões políticas, econômicas e sociais. Esses estudiosos compartilharam a ideia de negar a suscetibilidade genética (RABUFFETTI, 1999).

\section{RELAÇÃO IMPLÍCITA ENTRE A TEORIA DE LOMBROSO E O RACISMO VELADO NO BRASIL}

Embora a Academia Alemã de Criminologia tenha desenvolvido uma teoria moderna do crime, ela ignorou a pesquisa eugênica de Lombroso e atribuiu a essas diferentes críticas da Europa continental, mas na América Latina, a ideia de "criminoso" recebeu muitos Os seguidores iniciaram pesquisas relacionadas à criminologia no hemisfério sul. Sem levar em conta as críticas levantadas pelas ideias de criminosos nascidos na Europa, estudiosos brasileiros como Viveiros de Castro e João Vieira de Araújo têm amplamente Publicou a pesquisa de Lombroso e apontou que esses estudos são muito importantes para a compreensão de crimes e criminosos (MERELES, 2013).

Segundo (MERELES, 2013):

Se não é possível apontar com absoluta precisão quem foi efetivamente o pioneiro nos estudos da criminologia no Brasil, é interessante ressaltar que tanto a reivindicação do pioneirismo no novo campo quanto a busca de reconhecimento internacional cedo se colocaram como importantes elementos de legitimação e distinção entre os pensadores que começavam a trabalhar com as novas teorias. Viveiros de Castro, por exemplo, chama para si o mérito de ter apresentado o primeiro livro de divulgação das novas ideias no Brasil (Viveiros de Castro, 1894:14), ao passo que Cândido Mota, na apresentação da reedição de seu livro Classificação dos Criminosos, cita, entre os muitos elogios feitos ao seu trabalho no Brasil e no exterior, a suposta aprovação do próprio Lombroso - maior glória possível para os discípulos das novas teorias criminológicas (MERELES, 2013). 
Criada uma cultura para estudar criminosos como uma pessoa complexa, sua biologia física e aspectos espirituais determinarão sua atitude. Portanto, a atenção à pesquisa criminal não prestou atenção a aspectos como desigualdade social, oportunidades desiguais, falta de recursos em saúde e educação e falta de acesso à moradia. Por esse fato, Alvarez disse que a pesquisa sobre crimes e criminosos estabeleceu uma forte fonte de eugenia e preconceito. Essas raízes entram ativamente nas minorias étnicas brasileiras em risco e são caracterizadas por "criminosos brasileiros", negros, negros, mulheres, homossexuais e moradores de comunidades formadas por urbanização exclusiva (PEREIRA, 2018).

\subsection{O RACISMO VELADO NO BRASIL}

O racismo oculto é o racismo de comportamento disfarçado e sutil, o agressor geralmente não percebe que está danificando os direitos e a honra da vítima. Essa abordagem discriminatória é generalizada no Brasil e muitas vezes leva à existência a longo prazo de racismo entre gerações. Nesse sentido, o autor acima mencionado disse o seguinte sobre costumes mascarados, uma pessoa que trabalha à beira da invisibilidade trabalha sutilmente sem comprometer a suscetibilidade já considerada natural (OLIVEIRA, 2006).

O racismo mascarado é difícil de detectar, mesmo por suas vítimas, porque é disfarçado de "piada" e constitui um comportamento rotineiro e repetitivo na sociedade. Portanto, mesmo que a vítima perceba esse crime, ela finalmente decide abandonar a denúncia porque, segundo Pereira, é "difícil provar substantiva (a existência de elementos materiais que constituem uma característica criminosa) que enganar o racismo". "Seguindo essa linha de raciocínio, especialistas citaram exemplos de casos convencionais relacionados a esses crimes, a luta contra o racismo / preconceito no Brasil é mais difícil, porque esse comportamento não é revelado pelos praticantes de maneira "aberta", mas oculta. Segundo ele, as pessoas geralmente estão acostumadas a enfrentar discriminação e começaram a considerar comportamentos normais, como "deportar uma criança negra de uma loja porque ela pode estar implorando". Além disso, o repórter também mencionou as expressões comumente usadas pelos brancos em nosso país, como "este é um homem negro 
com uma alma branca", "ele é um homem negro, mas é um homem bom", "ele só pode ser um homem negro" (NASCIMENTO, 2010).

\subsection{RELAÇÕES ENTRE A TEORIA DE LOMBROSO E O RACISMO VELADO NO BRASIL}

O Partido Criminológico Positivista Criminológico, composto por Cesare Lombroso, Enrico Ferri e Rafael Garofalo, fez a Lei Penal Brasileira Teve um impacto enorme. Portanto, o Código Penal de 1890 tem óbvia inspiração positivista, o que levou à disseminação de idéias positivistas, incluindo o Código Penal de 1940, que desencadeou incitação ao atual Código Penal em meados do século XXI. Por exemplo, podemos nos referir ao artigo 59 do Código Penal, que trata da personalidade dos criminosos, e ressalta que esse é um dos requisitos para a aplicação e agravamento de sanções. Em relação às medidas de segurança no código, Munanga explicou:

As medidas de segurança, presentes nos arts. 96 a $99 \mathrm{CP}$ não foram introduzidas diretamente pela escola positiva, mas são uma consequência do seu desenvolvimento, visando proteger a sociedade contra a periculosidade do agente. Vale ressaltar que a lei é um instrumento de controle social, e que mesmo nos dias atuais observamse grupos e classes sociais marginalizados, que sofrem o estigma de serem controlados ou afastados do convívio socia (MUNANGA, 2004).

Portanto, de acordo com os autores, fica claro que a pesquisa positivista sobre Lombroso é a razão para estabelecer um controle social positivo de grupos marginalizados, porque, de acordo com o senso comum e as leis, isso trará maiores riscos à sociedade Mercadorias e ordem. Como resultado, milhares de pessoas pobres, negros e homossexuais foram rotulados com o termo "vagabundos" (MOTA, 2007).

Portanto, foi observado como o Direito Penal criou um ambiente favorável para a disseminação do racismo em várias formas e ações. Segundo ele, enquanto houver um "Código" baseado em preconceito e discriminação, o racismo não falhará, 
aprisionando centenas de negros e pobres com "personalidades suspeitas e perigosas" (VIEIRA, 2008).

\subsection{SOLUÇÕES PARA A REDUZIR AS PRÁTICAS RACISTAS}

Os principais problemas sociais causados pelas práticas contra o racismo está presente desde a promulgação da Constituição Federal de 1988, a luta contra o racismo avançou e políticas de longo prazo foram aplicadas, como cotas raciais em Oliveira disse, no entanto, que as agências governamentais ainda precisam fazer muito trabalho para que a população negra não sofra mais danos verbais, físicos e psicológicos. Além disso, o repórter citou a violência econômica sofrida pela população de ascendência africana, universidades e concursos públicos e criminalização do racismo por ser insustentável. é caracterizada pela desigualdade salarial entre trabalhadores brancos e negros. A renda média dos primeiros é de $\mathrm{R} \$$ $2.757,00$ e a renda média dos negros é de $R \$ 1.531,00$. Outro dado apresentado por este repórter é que, entre as populações pardas e negras, o número de desempregados permanece alto, equivalente a 8,3 milhões dos 13 milhões. Além disso, segundo pesquisa da jornalista Isabela Vieira (2015), a proporção de negros e pardos em universidades públicas e privadas do país é de $25,6 \%$, o que representa menos da metade da população branca (SILVA, 2010).

Ao analisar outra questão relacionada a questões raciais e preconceitos, analisaram um problema que expunha dados como o número de negros e pardos mortos pela polícia no Brasil igual ao número de brancos mortos por eles Três vezes o número. Agências de prevenção e investigação, em relação a essa questão policial, destacando que a gendarmaria não estava preparada para agir nos estados vizinhos do Brasil, o treinamento inspirou a polícia a agir violentamente contra aqueles que foram acusados pela sociedade de pobreza, ladrões e injustiças, muitos dos quais fazem parte da população negra e parda, as pessoas com as mais desiguais oportunidades em nosso país, sofre mais, portanto, estes farão parte das mais altas estatísticas de mortes de policiais (SANTOS, 2014). 
As principais medidas adotadas pelo governo brasileiro para reduzir o racismo estão relacionadas a políticas de ação afirmativa, como cotas raciais para admissão em universidades federais e órgãos públicos. Além disso, Afonso citou políticas afirmativas destinadas a garantir a igualdade financeira entre os cidadãos brasileiros, como abono de família e fome zero. Com relação ao significado do termo "política de igualdade de ação", essas políticas visam acabar com as desigualdades sociais acumuladas historicamente, promovendo ações que visem proporcionar "oportunidades iguais para grupos historicamente desiguais". O autor afirma que os escravos negros de 500 anos de idade no território brasileiro criaram a instabilidade de centenas de milhares de negros e pardos no Brasil, que é a obrigação do país de reduzir doenças nesse processo histórico (SANTORO FILHO, 2015).

Devido à importância dessas ações afirmativas, é vital que o governo brasileiro adote mais políticas do mesmo tipo e qualidade para aprofundar sua influência. Além disso, os sindicalistas apontam que indivíduos e empresas que desrespeitam esses comportamentos devem ser punidos pelo Estado. Portanto, recomenda-se que o autor indique, conforme apontado pelo próprio governo federal, é necessário aprofundar os efeitos das políticas afirmativas por meio de uma gestão integrada e coordenada das ações. Políticas inclusivas devem ser promovidas no setor de emprego, incluindo serviços públicos e setor privado. No trabalho, aqueles que distinguem pessoas com base na cor da pele devem ser punidos de acordo com as disposições da Convenção Internacional da Organização do Trabalho No. 111 (Organização Internacional do Trabalho), que prevê discriminação indireta (RABUFFETTI, 1999).

Em relação às cotas raciais para admissão em universidades públicas, Carla, utilizou dados para mostrar resultados positivos dessas políticas, como o crescimento de negros públicos e o ensino superior gratuito em mais de 1000\% no período 19972011. Segundo dados Santos (2014) apenas $1,8 \%$ da população negra brasileira recebeu o ensino superior e, em 2011, essa proporção saltou para 11,9\%. Como um aprofundamento da política de cotas raciais, o repórter acima mencionado disse: "30,9\% das ofertas de emprego em agências federais e $22,4 \%$ das ofertas de emprego nas universidades são negras, pardas e aborígines, representando 1/3 e 1/4 do total 
de ofertas de emprego. Respectivamente. "Além disso, Meireles citou pesquisa realizada pelo IPEA e constatou que:

Segundo o Instituto de Pesquisas Aplicadas (IPEA), a taxa líquida de matrícula de jovens de 18 a 24 anos - que mede o número de matriculados no nível esperado de ensino para aquela faixa etária - mais que quintuplicou entre os negros. No Boletim Políticas Sociais: acompanhamento e análise $n \times 19$, também do IPEA - criado por ocasião da programação em torno do Ano Internacional dos Afrodescendentes no ano de 1992 - apenas 1,5\% dos jovens negros nesta faixa etária estavam na universidade. Em 2009, eram 8,3\%. A frequência dos jovens negros na universidade, que correspondia a $20,8 \%$ da frequência dos brancos em 2002, passou a corresponder a 38,9\% em 2009 (SANTOS, 2014)

Outra ação afirmativa importante para reduzir o racismo no Brasil é a implementação da Lei $n^{\circ} 10.639$ / 03, que torna obrigatório o ensino da história e da cultura afrobrasileiras, que será baseada em tópicos históricos. A luta entre a África e os africanos, a luta dos negros brasileiros, a cultura negra brasileira e os negros na formação da sociedade nacional e as contribuições dos negros nos campos social, econômico e político relacionados à história brasileira (OLIVEIRA, 2006).

\section{IDEIAS SUCESSORAS ÀS DE LOMBROSO}

Nos campos do direito penal, criminologia e medicina forense, a influência de Lombroso em seus sucessores é óbvia. Lombroso é principalmente no campo da antropologia criminal (ele é seu fundador) e ainda colabora na vida de Ferri e Garofalo. Seu sucessor mais próximo foi sua filha Gina Lombroso Ferrero, biógrafa e colaboradora, responsável pela disseminação inicial de ideias. De fato, Gina colaborou com o pai várias vezes (NASCIMENTO, 2010).

A outra filha de Lombroso, Paola, se destaca nos campos da educação e da psicologia infantil: sob a influência óbvia de seu pai destacado, ela escreveu muitas histórias infantis e criou a psicologia infantil. O marido de Paola, o famoso criminologista Mário Carrara, escreveu vários livros sobre direito penal e criminologia. Carrara também foi o diretor do Museu de Psiquiatria e Criminologia fundado por Lombroso em 1898. Lombroso tem cinco filhos, mas apenas Gina e Paola são famosos. Gina se casou 
com o historiador Guilherme Ferrero, que foi um grande promotor da teoria de Lombrosi (MUNANGA, 2004).

Infelizmente, a família de Lombroso foi perseguida por causa de descendência israelense e foi forçada a se refugiar na Suíça, o que interrompeu o trabalho de promoção do trabalho do mestre. A princípio, a Itália fascista não tinha significado antissemitismo, mas o tratado com a Alemanha nazista permitiu que o país continuasse a perseguição aos judeus. Apesar da morte de Lombroso, sua família sofreu as consequências de sua origem (MOTA, 2007).

Os sucessores mais importantes de Lombroso e participantes do trabalho e pesquisa de grandes mestres são Garofalo e Ferri. Raffaelle Garofalo (1851-1920), juntamente com Lombroso e Ferri, fundou a Escola de Direito Penal e Positivismo da Criminologia. Ele acha que esse é um conhecimento relacionado ao crime e ao direito penal, sua pesquisa previu a formação da psicologia criminal (MOLINA, 1999).

Por outro lado, Enrico Ferri (1856-1929), professor da Universidade de Turim, é advogado criminal e mais inclinado à sociologia. Isso é comprovado por seu trabalho mais importante: a sociologia do crime, publicada em 1892. Ele era membro do comitê que redigiu o Código Penal Italiano, mas o projeto do comitê foi substituído por outro comitê. Ferri e Ghanafaro, Ferrero, Carrara, Gina e Paul formaram figuras notáveis na escola ativa de direito penal, mas, como o pensamento forense estava se desenvolvendo em outra direção, essa escola tinha muitos poucos seguidores (MOLINA, 2013).

\section{SUPERAÇÃO DA MEDICINA LEGAL LOMBROSIANA}

Profissionais modernos de medicina legal acreditam que a teoria de Lombroso é fraca. A pesquisa sobre o crânio e os ossos ainda não chegou a uma conclusão clara sobre a relação entre ossos e comportamento mental. Esses fatos não são suficientes para provar que os seres humanos têm uma tendência genética (raciocínio) para cometer crimes devido à estrutura corporal (LOMBROSO, 1997). 
A pesquisa de Lombroso foi realizada há cerca de 150 anos, quando não havia recursos suficientes para a realização de exames, como o DNA. Lombroso não pode confiar em dados científicos mais seguros e que valem a pena confiar (MERELES, 2013).

Alguns de seus críticos até respeitam literatura, como a história dos irmãos corsos: eles estão ligados e compartilham o mesmo sangue. Eles são inerentemente conectados e separados um do outro. No entanto, eles vivem em ambientes diferentes, e cada pessoa formou seu próprio tipo de personalidade. Portanto, o criminoso pode nascer com certos personagens depravados, mas seus esforços e 0 modo de educação podem mudá-lo. Portanto, a humanidade é um produto do ambiente do qual ele depende para a sobrevivência e o desenvolvimento. Ele pode ficar doente, mas pode ser curado e, a propósito, Lombroso nunca negou (GUIMARÃES, 2005).

Segundo os criminosos, o infrator deve ser encaminhado a um médico, e não a um juiz. Outros afirmam que muitos criminosos se recuperaram, enquanto outros tiveram uma vida normal e, portanto, entraram em uma vida criminosa no início de suas vidas. Podemos resumir alguns fatos isolados. Essa é a razão da curta duração da faculdade de direito criminal positivo, e o reavivamento muitos anos depois mudou o padrão originalmente adotado por Lombroso, no entanto, o mundo inteiro é respeitado por Lombroso, como a cidade de São Paulo, que se chama "Cesar Lombroso (uma rua perto de Bom Retiro). Professor César Lombroso) (CARVALHO, 2010).

Mas, como os próprios críticos admitem, Lombroso tem inúmeras conquistas. Ele aprendeu com entusiasmo sobre o crime, suas causas e a figura dos criminosos e conduziu anos de pesquisa sem desbotar com uma atitude séria e dedicada. Muitas de suas conclusões são relevantes e úteis na lei. Seu compromisso em encontrar as causas do crime e seus remédios é notável: ele também tenta entender os criminosos e suas diferenças em relação às pessoas comuns (CALEGARI, 2007).

Também deve ser salientado que não apenas fatores genéticos brutos influenciaram as tendências do crime. Lombroso analisou e citou meio ambiente, educação, clima e 
vários outros fatores. O livre arbítrio não está descartado. Portanto, existem muitos fatores que afetam a composição dos criminosos (BITENCOURT, 2011).

No entanto, um fato foi confirmado pela psicologia moderna e por muitas teorias médicas e psicológicas: existe uma conexão entre a física e a psicologia, ou seja, a conformação física pode levar a características psicológicas e espirituais e vice-versa. Por outro lado, o sucessor de Lombroso defendeu a teoria de que fatores psicológicos influenciam a formação física e as características físicas. Por exemplo, a vida de um criminoso termina na formação de características físicas; dessa maneira, o criminoso pode trazer à sua face os traços marcantes de sua vida encantadora, desacordos com dor, ciúme, desobediência, resistência, vingança, ódio, família, trabalho e outros ambientes humanos podem levar a disfunções fisiológicas, como diabetes, úlceras, estresse, pressão alta, colesterol elevado e outros fatores patológicos (AFONSO, 2014).

\section{A PERSISTÊNCIA DAS IDEIAS LOMBROSIANAS NO SÉCULO XXI}

A ligação dos criminologistas contemporâneos com o lombrosionismo pode estar atrelada à propagação dessa teoria em outras áreas de conhecimento como Sociologia, Antropologia, História, Medicina e Direito. A roupagem atual da discussão ainda se debruça nas explicações sobre violência, identificação forense e métodos preventivos da delinquência, pode explicar a combinação da criminologia de Lombros e o presente. Desde o século 19, em seu curso de graduação em direito, a criminologia tem sido objeto de discussão sobre a origem do direito penal positivista. O fundador da antropologia criminal, Cesare Lombroso, e a tendência criminosa das características anatômicas humanas, ajudam a desenvolver estereótipos e métodos de reconhecimento científico de cerco. Os especialistas julgam os objetos analisados antecipadamente. Tudo está sempre deformado, assimetria ou estigma desavergonhado (DEL OLMO, 2004).

Em outro trecho do mesmo artigo, Arthur Carvalho estabeleceu seu discurso lambertiano ao distinguir bons cidadãos de maus indivíduos: 
O problema social é uma coisa, índole má é outra. (...) A situação como está é que não pode continuar. $O$ cidadão pacato e de bem, que paga imposto, produz para a nação e tem família para criar não deve ficar a mercê da bandidagem, de um pivete qualquer, que tire sua vida covarde e impunemente. A certeza da impunidade é um incentivo ao crime. A literatura brasileira e a estrangeira são ricas em personagens lombrosianas - pessoas intrinsecamente perversas que nasceram propensas à prática de crimes escabrosos. (CARVALHO, 2010)

Esse argumento remonta à narrativa criminológica do século $\mathrm{XIX}$, sobreviveu às críticas e mudanças do século XX e continua sendo eficaz nos métodos forenses do século XXI. O medo do comportamento antissocial está relacionado à necessidade humana de estabelecer um mecanismo para disciplinar os cidadãos, como escolas, prisões, hospitais psiquiátricos, orfanatos, etc. Esses são e ainda são redutos de ordem e controle. Ao modelar o comportamento da população por meio dessas instituições, o poder do Estado busca se legitimar, construindo assim os conceitos de ordem pública e parâmetros morais (GUIMARÃES, 2005).

Gradualmente, o conceito e o método de identificação da justiça legal tornaram-se legais e passaram a ser aceitos pelo público como um mecanismo necessário para a implementação do poder do Estado, no entanto, devemos perceber que a justiça é um produto da construção cultural, que difere de acordo com o conceito de crime e os parâmetros culturais da sociedade em que é usada. Quando entendermos essa variante teórica, nos ateremos ao direito penal definido de acordo com as necessidades de cada grupo social. A padronização das penas abriu espaço para outras ciências dedicadas à pesquisa forense, que tentaram adaptar o corpo humano às regras do direito penal (BERARDINELLI, 1938).

O corpo humano é dominado pelo aparecimento da vigilância social, mas agora, sem ser diretamente punido pelo corpo, o corpo humano se tornará alvo do estigma repulsivo expresso pela teoria dos meios de identificação aprimorados. Representa uma transição do antigo molde de tortura punitivo para limpar penas, sem sangue, sem tortura, mas cheio de penas estereotipadas (VIEIRA, 2008).

O estigma espalhado por essas palavras reflete ideias estereotipadas que ainda permeiam parte de nossa sociedade exclusiva. De certa forma, ainda hoje, ainda 
descobrimos que pessoas que associam o caos urbano a algum tipo de desvio congênito estão associadas à "naturalidade" desse crime (SANTOS, 2014).

\section{CONSIDERAÇÕES FINAIS}

Através do estudo de Cesare Lombroso e do racismo direto no Brasil, pode-se ver claramente como os princípios e características das obras de Lombroso são por meio de mecanismos sutis de discriminação mantenha-se ativo em nossa sociedade, eles estão constantemente se movendo no cotidiano dos estados brasileiros através do comportamento racista contra as minorias.

Como resultado, fica claro que a solução para reduzir essas práticas racistas é principalmente estabelecer políticas de ação afirmativa profunda em todo o território brasileiro para reduzir os problemas causados pela escravidão e pela escravidão e outros processos históricos obras de eugenia como "O Homem Delinquente".

\section{REFERENCIAS}

AFONSO, Jacy. Combate ao racismo exige igualdade de oportunidades. 2014. Disponível em: <https://www.brasil247.com/pt/247/artigos/180713/Combateaoracismo-exige-igualdade-de-oportunidades.htm > Acesso em: 12 de julh. 2020.

BITENCOURT, C. R. Tratado de Direito Penal, Parte geral I. São Paulo: Saraiva, 2011.

BERARDINELLI, W. Biotipologia Criminal. Rio de Janeiro: Ed. Guanabara, 1938

CALEGARI, Luiza. Número de negros mortos por policiais é o triplo do de brancos. Disponível em: < https://exame.abril.com.br/brasil/numero-de-negrosmortos-porpoliciais-e-o-triplo-do-de-brancos/ > Acesso em: 12 de julho. 2020

CARVALHO, Phillipe. Racismo e direito penal: Análise de uma relação fabricada. Disponível em:<https://phillippecarvalho.jusbrasil.com.br/458602569/racismoedireito-penal-analise-de-uma-relacao-fabricada> Acesso em: 12 de julho. 2020 
DEL OLMO, Rosa. A América Latina e sua Criminologia. Rio de Janeiro: Revan: ICC, 2004.

DEMIRANDA, Dandara. O direito penal brasileiro e as contribuições das escolas clássica e positiva. Revista Âmbito Jurídico. 2015.Dísponivel em: < http://www.ambitojuridico.com.br/site/?n_link=revista_artigos_leitura\&artigo_id=1940 8\&revista_cadern $0=3>$ Acesso em: 12 de julho. 2020

GIFE- ORG. Lei que torna obrigatório ensino da História e Cultura Afro-brasileira completa 15 anos. Disponível em: <https://gife.org.br/lei-que-tornaensino-da-historiae-cultura-afro-brasileira-completa-15-anos/> Acesso em: 17 de julho. de 2020.

GUIMARÃES, Thiago. Treinamento Policial. Disponível em: < https://www.bbc.com/portuguese/noticias/2016/01/151231_treinamento_policia_tg > Acesso em: 12 de julho. de 2020.

LOMBROSO, Cesare. O Homem Delinquente. 3ํReimpressão. Ícone. 1997.

MERELES, Carla. Cotas raciais no Brasil e o que são. Disponível em: < https://www.politize.com.br/cotas-raciais-no-brasil-o-que-sao/ > Acesso em: 17 de julho. de 2020.

MOLINA, de Pablos, Garcia, Antonio. Tratado de Criminología. 2ª ed, São Paulo,1999.

MOLINA, de Pablos, Garcia, Antonio. O que é a criminologia?1. ed. São Paulo: Revista dos Tribunais, 2013.

MOTA, Jorge, Maurício. O Crime segundo Lombroso. Disponível em: $<$ https://criminologiafla.wordpress.com/2007/08/20/aula-2-o-crime-segundolombrosotexto-complementar/> Acesso em: 17 de julho. de 2020.

MUNANGA, Kabemgele. Racismo Velado. Disponível em: < https://jornalggn.com.br/blog/luisnassif/o-racismo-velado-por-kabengele-munanga > Acesso em: Acesso em: 12 de julho. de 2020. 
NASCIMENTO, Gustavo. Como Identificar o Racismo Velado. Disponível em: < https://www.geledes.org.br/o-racismo-velado-por-gustavo-nascimento/ > Acesso em: 17 de julho. de 2020.

OLIVEIRA, Guilherme. País ainda precisa avançar no combate ao racismo. Disponível em: < ttps://www12.senado.leg.br/noticias/especiais/especialcidadania/pais-aindaprecisa-avancar-no-combate-ao-racismo/pais-ainda-precisaavancar-no-combate-aoracismo > Acesso em: Acesso em: 12 de julh. de 2020.

PEREIRA, Tatiane. O Racismo Velado. Disponível em: < https://tribunademinas.com.br/opiniao/tribuna-livre/13-05-2018/racismo-velado.html > Acesso em: 17 de julho. de 2020.

RABUFFETTI, M. Breve ensaio acerca das principais escolas criminológicas. São Paulo, 1999.

SANTORO FILHO, Antonio Carlos. Conceito de Política Criminal. Revista Jus Navigandi, Teresina. 4549, 15 dez. 2015. Disponível em: <https://jus.com.br/artigos/43624>. Acesso em: 12 de julho. de 2020.

SANTOS, Bartira. LOMBROSO NO DIREITO PENAL: o destino d'O Homem Delinquente e os perigos de uma ciência sem consciência. Revista Publica Direito. 2014.

SILVA, da Martins, Fernando, Luiz. Políticas de ação afirmativas para negros no Brasil: Considerações sobre a compatibilidade com o ordenamento jurídico nacional e internacional. Revista Palmares. 2010. Disponível em: < http://www.palmares.gov.br/wp-content/uploads/2010/11/Pol\%C3\%ADticasdea\%C3\%A7\%C3\%A3o-afirmativas-para-negros-no-Brasil.pdf Acesso em: 12 de julho. de 2020.

VIEIRA, Isabela. Percentual de negros em universidades dobra, mas ainda é menor que 0 de brancos. 2008. Disponível em: < http://agenciabrasil.ebc.com.br/educacao/noticia/2016-12/percentual-de-negros- 
emuniversidades-dobra-mas-e-inferior-ao-de-brancos > Acesso em: 12 de julho. de 2020.

Enviado: Janeiro, 2021.

Aprovado: Janeiro, 2021. 